\title{
A organização tópica no gênero artigo de opinião
}

\section{Topic organization in opinion article genre}

\section{Cleide Vilanova Hanisch ${ }^{1}$}

\begin{abstract}
Resumo: Inserido no quadro teórico-metodológico da Gramática Textual-Interativa (JUBRAN, 2015), este artigo trata do reconhecimento de uma unidade da língua fundamentalmente sistemática no âmbito da organização do texto. Para tal, investiga a Organização Tópica em artigos de opinião publicados em jornais, com o objetivo de avaliar se, nesse gênero, a organização intertópica e a organização intratópica, caracterizam-se como um processo regular, ou se é um processo fundamentalmente inconstante. A metodologia adotada segue o método da análise tópica, que presume a análise textual com base na categoria do tópico discursivo e demonstra que tanto no domínio da organização intertópica quanto no contexto da organização intratópica, os artigos de opinião, particularizam-se pela presença de traços altamente regulares passíveis de serem descritos em termos de organização tópica. Esses traços de regularidades permitem sustentar que o texto é fundado em propriedades constitutivas próprias.
\end{abstract}

Palavras-chave: Organização Tópica. Tópico discursivo. Gênero Artigo de Opinião.

\begin{abstract}
Considering the theoretical and methodological framework of Textual-Interactive Grammar (JUBRAN, 2015), this study emcompasses the attesting of a language unity designed into the extent of textual organization. Thus, this study Topic Organization focuses on opinion articles published in newspapers, aiming to demonstrate if in this genre, the intertopic and intratopic organization are composed as a regular process or if it is essentially a process of inconstant. The methodology applied follows the topic analysis in which consider a textual analysis based on the category of discursive topic, and demonstrates that an intertopic organization dimension and an intratopic organization context of the opinion articles are particularly characterized with high traces of irregularities from the descriptions in terms of topic orgnization. These traces of irregularities enable support that the text is composed with particular properties.
\end{abstract}

Keywords: Topic Organization. Discursive Topic. Opinion Article Genre.

\section{Introdução}

Neste artigo apresentamos e discutimos os resultados de uma pesquisa realizada com o processo de construção textual - Organização tópica - em artigos de opinião publicados em jornais. Procuramos demonstrar, aqui, a sistematicidade desse processo de construção textual em seus dois níveis de funcionamento, isto é, a organização intertópica e a intratópica nos artigos analisados.

\footnotetext{
${ }^{1}$ Universidade Federal do Acre, Centro de Educação e Letras, Cruzeiro do Sul, Acre, Brasil. Endereço eletrônico: cleide.hanisch@ufac.br.
} 
A adoção da organização tópica como unidade de análise funda-se em estudos desenvolvidos por vários pesquisadores no interior da Gramática Textual-Interativa (GTI, daqui em diante), uma vertente mais atual da Linguística Textual, os quais vem demonstrando a existência de uma unidade linguística no âmbito da organização textual, baseada em particularidades específicas de organização, que se diferem, por exemplo, daquelas manifestadas no nível da frase.

No que tange à organização intertópica, os estudos da GTI assumem que cada gênero pode diferenciar-se ou aproximar-se de outros em relação aos seguintes aspectos: predominância de unicidade intertópica (cada texto de um gênero é composto por apenas um tópico) ou de complexidade intertópica (cada texto constitui-se de mais de um tópico); grau predominante de complexidade hierárquica (representado pela quantidade de Subtópicos mínimos e de Quadros Tópicos em cada texto); tipo predominante de linearização entre os SegTs mínimos do texto.

Em relação à organização intratópica, admite-se que as particularidades de um gênero são demonstradas no modo como os Segmentos Tópicos Mínimos (SegTs mínimos) são estruturados, internamente, com base na combinação entre grupos de enunciados. Nessa direção, Penhavel (2010) constata que no caso, por exemplo, de relatos de opinião, material representativo de gêneros fundamentalmente $\operatorname{argumentativos}^{2}$ (como editoriais e artigos de opinião), os falantes estruturam os SegTs mínimos com base em uma alternância sistemática entre grupos de enunciados que constroem referências centrais e grupos de enunciados que constroem referências subsidiárias em relação à ideia central do SegT.

O presente estudo insere-se, exatamente, nesse contexto de comprovação da regularidade da organização textual, apresentando uma análise dos dois níveis de funcionamento da Organização Tópica, processo central de construção do texto reconhecido pela GTI, a fim de verificar, a título de exemplo, se essa organização nos mais variados gêneros, seria, com efeito, um processo sistemático, o que demonstraria, por sua vez, que o texto é uma atividade essencialmente estruturada e, como tal, apresenta regularidades específicas de organização.

\footnotetext{
${ }^{2}$ A título de esclarecimento, cabe aqui assinalar que reconhecemos o caráter argumentativo da linguagem, o qual se materializa em qualquer gênero textual (CAVALCANTE et al., 2019). Nesse sentido, ao considerarmos o artigo de opinião como um gênero basicamente argumentativo, o concebemos como um gênero primordialmente destinado à função particular de argumentar, ao contrário de outros gêneros que, embora sejam guiados por uma orientação argumentativa, têm outra finalidade primordial ou explícita.
} 


\section{A GTI e o processo de organização tópica}

A Perspectiva Textual-Interativa ou Gramática Textual-Interativa como uma proposta teórico-metodológica para a análise textual, surgiu a partir de estudos sobre o texto falado no contexto Projeto de Gramática do Português Falado desenvolvidos por um grupo de pesquisadores coordenados por Ingedore Grunfeld Villaça Koch, sistematizada particularmente em Jubran (2007, 2015a). No âmbito do projeto, esses pesquisadores enfrentaram o desafio de elaborar uma proposta de referência teórico-metodológica para o estudo dos processos de construção do texto, que assume o texto como objeto de estudo.

Sendo, assim, a GTI emerge como uma proposta de abordagem do texto, visto no seu processo de interlocução como o lugar onde é possível identificar regularidades de processamento de estruturas. Nesse contexto, essa perspectiva tem o papel de descrever o caráter sistemático dos procedimentos de construção textual, "aferido pela recorrência desses procedimentos em contextos definidos, pelas marcas formais que os caracterizam e pelo preenchimento de funções textual-interativas proeminentes que os especificam" (JUBRAN, 2007, p. 316). É, nesse sentido, que neste trabalho, assumimos que a identificação de regularidades no processo Organização Tópica em um gênero particular oferece subsídios não apenas para a validação da GTI como gramática do texto, mas, em especial, para a descrição textual-interativa do gênero artigo de opinião.

A base da proposta teórica sobre a qual essa perspectiva está assentada diz respeito à concepção de língua como forma de interação social, isto é, atividade verbal com a qual pelo menos dois interlocutores agem e expressam suas intenções com ações adequadas aos propósitos em cada intercâmbio comunicativo. No âmbito dessa concepção de língua, a GTI estabelece alguns princípios que orientam os estudos.

O primeiro princípio teórico-metodológico é o de que "os fatos nela considerados têm propriedades e funções definidas no uso, nas situações concretas de interlocução, coenvolvendo as circunstâncias enunciativas" (JUBRAN, 2007, p. 315). Pode-se dizer que esse princípio prevê, entre outras consequências, que a análise completa dos processos de construção textual depende de estes serem situados no contexto específico em que são utilizados.

Com base nesse primeiro princípio e na concepção de língua adotada, a GTI vem postulando que os processos de construção textual, em grande parte, são definidos pela função sociocomunicativa do gênero em que se manifestam, ou seja, estão relacionados às finalidades do gênero, tendo em vista que estes amalgamam ações particulares empreendidas por meio de textos. Daí o delineamento do presente estudo a um gênero particular, nesse caso, o artigo de opinião. 
O segundo princípio central da GTI, decorrente do primeiro, diz respeito ao entendimento de que os fatores interacionais são constitutivos do texto e inerentes à expressão linguística. Ou seja, postula-se que os dados pragmático-situacionais se introjetam no texto, de modo que o interacional é intrínseco ao linguístico. Nessa direção, considera-se que "as circunstâncias enunciativas que sustentam a ação verbal se mostram no próprio texto, por meio das escolhas comunicativamente adequadas à situação interativa” (JUBRAN, 2007, p. 317).

Dessa forma, como explica a autora, os elementos pragmáticos são vistos como fatores imanentes da construção do texto e de sua análise. Esses fatores, continua a autora, ao manifestarem na superfície do texto as condições enunciativas, revelam regularidades do processamento textual pelos interlocutores e, assim, sustentam a admissão e a identificação de sistematicidade no processo de construção textual. É, nesse sentido, que esse princípio desempenha um papel primordial na GTI e, inclusive, no presente estudo, na medida em que fundamenta nossa premissa de que seria possível identificar regularidades no processo de organização tópica, no âmbito de um gênero textual particular.

À luz dos pressupostos teórico-metodológicos acima descritos, a GTI estabelece-se como uma abordagem que toma o texto como objeto de estudo, a fim de investigar o processo de Organização Tópica, de modo particular, além de outros processos, tais como Repetição, Correção, Parafraseamento, Parentetização, Tematização/Rematização e Referenciação, assim como, os mecanismos encarregados de gerenciar o funcionamento desses processos, os chamados marcadores discursivos.

Considerando que o objeto de investigação neste trabalho é o processo central de construção textual - Organização Tópica - na discussão esboçada na seção, a seguir, enfocamos tal processo.

\section{Princípio central de construção do texto: a organização tópica}

Os estudos desenvolvidos no âmbito da GTI têm demonstrado a Organização Tópica como processo fulcral na organização do texto - fio unificador e estruturador que perpassa todo o texto e, por isso, está presente em qualquer texto, ou seja, mostra-se "como um princípio organizador do discurso, que apresenta, no plano de sua realização, uma estrutura passível de ser identificada e descrita" (JUBRAN, 1993, p. 64).

Esse processo funda-se na organização do texto por meio da construção e articulação linear e hierárquica de grupos de enunciados formulados por interlocutores a respeito de um conjunto de referentes, concernentes entre si e em relevância num determinado ponto do texto (cf. JUBRAN, 2015b; PINHEIRO, 2005). 
Conforme realçamos, tal processo apresenta dois níveis de funcionamento - o intertópico e o intratópoico. O processo intertópico compreende a divisão do texto em tópicos e subtópicos, de acordo com a sua estruturação temática, isto é, trata da divisão do texto em partes e subpartes, as quais são denominadas de Segmentos Tópicos (SegTs), sendo as menores subpartes chamadas de SegTs mínimos ${ }^{3}$. Assim, pode-se dizer que a organização intertópica abrange a articulação entre SegTs mínimos.

O processo de Organização Tópica como um todo e, principalmente, a organização intertópica define-se por duas propriedades particularizadoras: a centração e a organicidade.

A centração consiste no inter-relacionamento de enunciados de um segmento textual cujos referentes mantêm entre si uma relação de interdependência semântico-pragmática, que assegura a convergência dos enunciados para um assunto proeminente, ou seja, para um eixo temático. Essa propriedade, segundo Jubran (2015b), compreende os traços de concernência (relação de interdependência semântica entre os enunciados de um segmento textual, pela qual se dá a integração desses enunciados em um conjunto específico de referentes - objetos-dediscurso); relevância (proeminência desse conjunto, decorrente da posição focal assumida pelos elementos) e pontualização (localização desse conjunto, tido como focal, em determinado momento do texto, considerando a concernência e a relevância de seus elementos interacionalmente instaurado).

A organicidade diz respeito às relações de interdependência tópica, isto é, aos desdobramentos de um tópico em subtópicos. Tal propriedade se estabelece em dois planos: a organização hierárquica e linear ou sequencial. A primeira estabelece no texto as relações de dependência de superordenação e subordinação entre tópicos discursivos que se relacionam pelo grau de abrangência do assunto. ${ }^{4}$ Ou seja, essas relações instauram em um texto a possibilidade de divisão do tópico global em tópicos mais específicos, da possibilidade de divisão destes em outros mais específicos ainda, e assim sucessivamente, configurando, pois, níveis de hierarquização na organização tópica (JUBRAN, 2015b).

Desse modo, nesse plano, os tópicos se relacionam como "Supertópicos" (ST) e "Subtópicos" (SbT), na medida em que os STs expressam maior grau de abrangência do assunto em pauta e os SbTs comportam maior grau de particularização do assunto (correspondentes,

\footnotetext{
${ }^{3}$ Pode-se dizer que, os SegTs mínimos, de modo simplificado, são unidades que equivalem a trechos de textos correspondentes, usualmente, a um, dois ou três parágrafos, no caso de um gênero escrito como o artigo de opinião. ${ }^{4}$ Nos estudos sobre a organização tópica, comumente, o termo "tópico discursivo", (ou apenas "tópico") pode ser conceituado como o tema (o assunto) - de um texto ou parte de um texto - interacionalmente produzido pelos interlocutores em um cenário social de construção textual.
} 
então, aos segmentos identificados como SegTs mínimos, também, denominados de SbTs mínimos) também como compondo, assim, níveis de hierarquização na estruturação tópica.

A organização sequencial diz respeito às relações que se estabelecem entre os tópicos, no que tange à sua disposição na linha discursiva. O estudo desse processo envolve, particularmente, a análise dos diferentes modos de sequenciamento entre SegTs mínimos, os quais compreendem especialmente as estratégias de (i) continuidade tópica e (ii) descontinuidade tópica - esta última incluindo a as estratégias de ruptura, cisão e expansão tópicas.

A organização intratópica, processo que compõe o segundo nível de funcionamento da organização tópica, concerne ao modo como os SegTs mínimos, isto é, "unidades linguísticas de organização textual" (PENHAVEL; DINIZ, 2014, p. 22), depreendidos na linearidade textual, se estruturam internamente, ou seja, diz respeito à articulação (de grupos) de enunciados no interior dos SegTs mínimos. Consiste, portanto, na combinação potencialmente recursiva entre (grupos de) enunciados dentro do SegT mínimo. Nos estudos conduzidos no âmbito da GTI, os estudos têm demonstrado que a organização intratópica exprime uma estruturação específica de cada gênero ou conjunto de gêneros.

Em estudo específico sobre esse processo, Penhavel (2010) analisou SegTs mínimos de relatos de opinião, extraídos de um banco de dados de entrevistas sociolinguísticas (corpus Iboruna - cf. GONÇALVES, 2007). Nesse estudo, o autor constata que, nos relatos de opinião analisados, a estruturação interna de SegTs mínimos se configura como um processo altamente regular. Segundo o autor, os SegTs mínimos investigados são estruturados, em sua grande maioria, com base em um mesmo princípio, que presume a combinação entre grupos de enunciados que constroem referências centrais e grupos que constroem referências subsidiárias relativamente ao tópico do SegT mínimo. Os grupos de referências centrais foram denominados de Posição e os grupos subsidiários, de Suporte. O autor observa que os grupos de enunciados que funcionam como posição ou suporte podem também ser estruturados internamente com base na relação posição-suporte, desse modo, denominou essa relação como a recursividade do padrão posição-suporte.

No exemplo da figura 1 que descrevemos, a seguir, é possível entender como ocorre a relação posição-suporte. 
Figura 1 - Relação posição-suporte

(1) Bom e isso é uma parte d/ da adolescência, mas é claro que a gente não tem ... só isso claro que tem aquelas pessoas que sabem aproveitar (sabe) aquelas pessoas que tão sempre contando... com a mãe... com o pai com a família... que é/ com o namorado claro mas o namorado também acho que (não) tem que ser tudo na vida a gente tem que... saber ter amigos saber aproveitar...

Ir numa balada não precisa beber tudo que tem na balada... bebe o:: tem/ o:: tanto que você acha que você vai aguentar... o tanto que você acha que vai ser legal para Você se divertir não para você passar mal.../porque o bom de uma balada não é você beber e depois sair vomitando e ficar... né todo mundo lá te olhando feio tal... (inint.) o legal é você beber pra ficar alegre... pra brincar não pra ficar estúpido com ninguém e tal... (PENHAVEL, 2010, p. 62).

Fonte: elaborada pela autora (2019).

Penhavel (2010) identifica o tópico do SegT na figura 1 como Saber aproveitar a adolescência. Nota-se que o trecho compreendido nas linhas 1-4 expressa esse tópico de modo direto (o que fica mais evidente nas passagens sublinhadas). Já o trecho envolvido nas linhas 59, expressa, de forma particular, aspectos característicos desse tópico, na medida em que, nesta segunda parte, a informante especifica o tópico apresentado no primeiro trecho: defende o consumo moderado de bebidas em baladas (vejam-se, sobretudo, as passagens sublinhadas nesse trecho), o qual pode ser entendido como um exemplo de bom aproveitamento da adolescência.

É a relação presumida da variação entre grupos de enunciados que constituem referências centrais e grupos que constituem referências específicas relativas ao tópico do SegT que possibilita assegurar que a organização intratópica desse SegT se funda na relação posiçãosuporte. Assim sendo, os enunciados nas linhas 1-4 se configuram como unidade de posição que tratam, de modo mais direto, o tópico do SegT. Já os enunciados expressos nas linhas 5-9 estabelecem a unidade de suporte que manifesta aspectos mais particulares desse tópico.

De acordo com Penhavel (2010), a recursividade da relação posição-suporte instaura, no interior de um SegT, uma unidade denominada como domínio de estruturação intratópica, isto é, uma unidade formada por uma posição e seus respectivos suportes. Segundo o autor, o SegT como um todo por si próprio se configura como um domínio, visto que sua estruturação interna é fundada nessa relação. Assim, a cada momento que uma unidade de posição ou de suporte se subdivide, fundada na própria relação de estruturação intratópica, um novo domínio emerge, isto é, é estabelecido. No SegT, em (1), por exemplo, pode ser reconhecida a presença de um domínio (linhas 1-9), estruturado conforme a combinação posição (linhas 1-4) - suporte (linhas 5-9).

Com base nas propriedades aqui discutidas, focalizaremos os dois níveis de funcionamento da Organização Tópica em artigos de opinião, conforme demonstramos a partir da seção seguinte. 


\section{A organização tópica em artigos de opinião}

Nesta seção discutimos os resultados dos dados da nossa pesquisa, avaliando se, nesse gênero, a Organização Tópica, de fato, constitui-se como um processo fundamentalmente sistemático que poderia, portanto, ser caracterizado, com base em seus dois níveis de análise a organização intertópica e a organização intratópica. Para tal propósito, incialmente, delineamos brevemente a constituição do corpus da pesquisa e os dois passos metodológicos adotados no estudo.

A metodologia adotada segue o método da análise tópica (JUBRAN, 2015b; PENHAVEL, 2010; 2017), cuja análise desenvolvida com base nas propriedades de centração e organicidade, possibilita a identificação, em qualquer texto, do processo de Organização Tópica. Assim sendo, definimos os dois passos do método de análise.

O primeiro passo de análise orientou-se para o estudo do funcionamento da organização intertópica - divisão do texto em tópicos e SbTs mínimos ${ }^{5}$ - em um texto que circula na sociedade e efetivou-se a partir de sua subdivisão em duas estratégias metodológicas articuladas entre si. Na primeira, analisou-se a organização intertópica hierárquica. Na segunda estratégia, a análise focalizou a organização intertópica sequencial.

No segundo passo metodológico, a observação centrou-se mais de perto no estudo da organização intratópica de SegTs mínimos componentes dos artigos de opinião, isto é, na estruturação interna dos segmentos textuais.

Esses segmentos, por sua vez, desenvolvem os menores subtópicos do texto - os SegTs mínimos, por meio da apuração do modo como se materializam os traços que compõem a centração tópica - concernência, relevância e pontualização - no interior desses segmentos em um gênero textual definido.

O corpus selecionado no âmbito da presente pesquisa é constituído por 20 exemplares do gênero artigo de opinião extraídos de quatro jornais ${ }^{6}$ que circulam no estado do Acre,

\footnotetext{
${ }^{5}$ A título de esclarecimento, vale explicar que, usamos, em alguns momentos, a expressão "SbTs mínimos", e não "SegTs mínimos", porque, nesse caso, estamos no domínio da hierarquização tópica, que diz respeito a relações entre tópicos (temas), isto é, entre STs, SbTs (incluindo os SbTs mínimos). No que concerne à linearidade textual, ou seja, organização intertópica sequencial, falamos não de "SbTs mínimos", mas sim de "SegTs mínimos". É claro que "SbTs mínimos" e "SegTs mínimos" são conceitos correspondentes. Um SbT mínimo, que é um tópico (assunto, tema), é desenvolvido em um segmento textual (um conjunto de enunciados), segmento este que, então, constitui um SegT mínimo. Ou seja, o SegT mínimo é o trecho textual que desenvolve um SbT mínimo. Porém, dependendo de qual aspecto do processo de organização tópica se está focalizando, é adequado falar em "SbT mínimo" (organização intertópica hierárquica) ou em "SegT mínimo" (organização intertópica sequencial e/ou organização intratópica).

${ }^{6}$ Os artigos que compõem o corpus da pesquisa foram selecionados da seção de opinião do jornalismo impresso diário, publicado pela Internet. Selecionamos quatro jornais regionais de maior abrangência de nível estadual. Em relação à política editorial, esses jornais apresentam como prioridade o noticiário estadual. Cabe aqui esclarecer
} 
Opinião, Página 20, O Rio Branco e A Gazeta, coletados no período de julho a agosto de 2016.

Feitas as considerações sobre o corpus e a metodologia de pesquisa, passamos a discutir, a partir de agora, os dados acerca da Organização Tópica em artigos de opinião, especificamente, com a organização intertópica.

Em relação ao nível de organização intertópica, a pesquisa mostrou que foi a presença de complexidade intertópica que se manifestou como o traço particularizador do gênero investigado, dado que cada artigo de opinião analisado não é constituído apenas por um único tópico discursivo, mas, ao contrário, organiza-se mediante a divisão de um tópico global em SbTs mínimos. Tal constatação pode ser considerada como uma das particularidades da organização tópica do gênero em apreço, na medida em que, conforme vem sendo demonstrado em trabalhos na GTI, os gêneros podem se diferenciar uns dos outros, no que diz respeito à organização intertópica, por exibirem, como regra geral, unicidade (quando, em geral, cada texto contém um único tópico discursivo, sem divisão em SbTs) ou complexidade intertópica (quando normalmente cada texto possui um tópico global que se divide em SbTs).

Verificada, então, a presença da propriedade da complexidade intertópica no gênero em questão, analisamos, a partir de agora, os planos da organização intertópica hierárquica e sequencial.

No que diz respeito à hierarquização tópica - que consiste na instauração de relações de dependência de superordenação e subordenação entre tópicos em termos do grau de abrangência do assunto -, analisamos, como definido acima, o grau de complexidade hierárquica característico do gênero. Para proceder a essa análise, verificamos, em cada artigo, (i) a quantidade de SbTs mínimos (expressos em SegTs mínimos) e (ii) a quantidade de QTs.

Foi identificado que, na maior parte das vezes (50\% dos casos), ${ }^{7}$ os artigos de opinião dividem-se em três SbTs mínimos. Outros casos significativos apurados no corpus apontam que os artigos podem constituir-se de cinco SbTs mínimos (20\% dos casos), quatro (10\% dos casos) e seis, sete, oito ou nove SbTs mínimos (5\% dos casos para cada uma dessas três últimas possibilidades). Verificamos também que os casos menos frequentes incidem sobre a divisão dos tópicos globais em seis, sete, oito e nove SbTs mínimos (5\% dos casos).

que a seleção por distintos jornais não foi motivada por uma análise comparativa das possíveis distinções de investimento do artigo em tais jornais, contudo alcançar uma maior representatividade do gênero.

${ }^{7}$ Quanto à análise estatística, para obtenção desses resultados (percentuais) os dados foram submetidos à estatística descritiva. 
Para efeito de exemplificação, analisamos o artigo de opinião (figura 2), que ilustra o caso de complexidade intertópica hierárquica mais recorrente identificado no corpus, isto é, aquele em que o artigo é composto por três SbTs mínimos.

Figura 2 - Exemplo da complexidade intertópica hierárquica A pintura da paisagem para o golpe

[[SbT mínimo 1]] Há alguns dias, o Brasil começou a parecer um país agradável nos telejornais, especialmente no Jornal Nacional, notícias amenas e apresentadores serenos. Os jornais deixaram de falar de uma paisagem devastada e começaram a dar notícias boas: "Cresce o otimismo com a economia", anunciou o Datafolha divulgando uma pesquisa pouco convincente, tanto em aspectos políticos como econômicos. Agora, $50 \%$ querem que Temer fique, contra $32 \%$ que preferem a volta de Dilma. Em abril o instituto apurou que a maioria não queria Dilma nem Temer. 61\% aprovavam o impeachment dela, e 58\% o dele. Alguma fada deve estar protegendo Temer porque nada mudou no cenário que justifique tal guinada do sentimento popular. Nesta terça-feira, por sinal, ele deu um prazo de 20 dias para que seus ministros da área econômica apresentem medidas para estimular o crescimento. Tal prazo termina quando? Em agosto, ora, bolas. E tem a Olimpíada, que absorverá muita luz nas próximas semanas, deixando em segundo plano os problemas reais. Não há dúvida: começou a ser pintado, com cores suaves, um quadro de otimismo para favorecer a consumação final do golpe revestido de impeachment em agosto. Uma pintura em aquarela, com muita cor borrada e pouca nitidez das formas.

[[SbT mínimo 2]] Na política, o Governo emplacou Rodrigo Maia na presidência da Câmara para tocar sua agenda conservadora, começando pela PEC que aprisiona o crescimento do gasto público no índice da inflação e pela reforma previdenciária. Da agenda de agosto Temer tratará esta noite num jantar com Rodrigo e Renan Calheiros, presidente do Senado. Quando o Congresso reabrir, no início de agosto, Meirelles e sua equipe estarão apresentando medidas pró-crescimento. Se elas fossem de fato possíveis e viáveis, já estariam sendo aplicadas, não estaria o governo perdendo um precioso tempo. Não importa o recheio do bolo, importa que tenha um glacê vistoso, que agora começará a ser preparado com muito açúcar.

Até o FMI apareceu neste início de semana informando que a recessão pode acabar sendo alguns décimos menores este ano, em relação ao que previra, e que em 2017 haverá crescimento, ainda que seja apenas de $0,5 \%$. Mas nada como o Datafolha, ao informar que os otimistas com a economia são $38 \%$, contra $30 \%$ de pessimistas. E numa contradição com os $60 \%$ que esperam aumento da inflação e do desemprego. Mas o que importa é a manchete, e ela falou de aumento do otimismo econômico.

$\mathrm{Na}$ linha do otimismo, apesar da inflação, do desemprego e do paradeiro nos negócios, fomos também informados de que:

- A Caixa Econômica Federal voltará a financiar imóveis para a classe média.

- Temer pediu à equipe econômica que reduza os juros.

- As exportações podem ter um superávit de US\$ 46,934 bilhões na balança comercial deste

ano.

- Segundo a CNI, o Índice de Confiança do Empresário Industrial teve a terceira alta seguida em julho, passando de 45,7 pontos para 47,3.

- Segundo o Credit Default Swap (CDS), com a posse de Temer o risco Brasil caiu significativamente, passado de 495,09 pontos em dezembro passado para 294,35 neste mês de julho.

[[SbT mínimo 3]] Muito mais pode ser encontrado numa garimpagem do noticiário econômico. Enquanto isso os congressistas aproveitam as férias e voltarão para trabalhar três dias por semana em agosto. No Senado, depois deste banho de cheiro e otimismo, será mais fácil confirmar a condenação de Dilma. A democracia? Seria problema se houvesse milhões nas ruas cobrando respeito ao voto, como na Turquia, mas aqui tudo segue na santa paz dos trópicos. O golpe não foi feito com tanques, o que gera indignação e revolta, mas com leis. Leis retorcidas e interpretações convenientes, mas com leis. E isso gera resignação e não revolta (A pintura da paisagem para o golpe, Página 20, 19 jul. 2016).

Fonte: Elaborada pela autora (2019).

De acordo com nossa análise, o artigo de opinião em pauta apresenta o tópico global 
se que, ao longo de todo artigo, são construídas expressões referenciais e enunciados, que se entrelaçam, estabelecendo referências em torno desse tópico, conforme se pode verificar nas seguintes expressões: “o Brasil começou a parecer um país agradável nos telejornais” (linhas 1-2), "Meirelles e sua equipe estarão apresentando medidas pró-crescimento" (linha 19), "a recessão pode acabar" (linha 23) e "o risco Brasil caiu” (linha 36).

O primeiro tópico (linhas 1-37) centra-se em introduzir a situação-problema, indo de uma apresentação de notícias boas e dados agradáveis até uma sutil crítica à preparação de um cenário favorável ao impeachment. Assim, convencionou-se intitular esse primeiro tópico (tópico 1) como Delineamento de cenário otimista para impeachment. Considerando-se as cadeias de referentes, é possível perceber seus limites e a abrangência de seus tópicos, levando a reconhecer que esse tópico se subdivide em outros dois, mais específicos: tópico 1.1 (SbT mínimo 1) e tópico 1.2 (SbT mínimo 2).

No SbT mínimo 1 (linhas 1-14), identificado como Desenho de quadro otimista: divulgação de apenas notícias boas os enunciados confluem para a projeção de um cenário otimista de consumação do golpe final, ou seja, o impeachment da então presidente Dilma Rousseff. No início desse SbT, destaca-se o papel dos telejornais, sobretudo, o Jornal Nacional, na divulgação de notícias boas que favoreceriam a projeção de tal cenário. Isso pode ser observado, por exemplo, nas linhas 1 e 2 . No decurso do desenvolvimento desse SbT, enfatizase uma série de fatos que corroboram a projeção de cenário otimista para impeachment, manifestados por meio de um conjunto de enunciados que instauram a propriedade da concernência em torno desses fatos, como se percebe em "Cresce o otimismo com a economia" (linhas 3-4) e "medidas para estimular o crescimento" (linha 9). Por fim, esboça-se uma inteligente crítica à projeção de tal cenário "começou a ser pintado" (linhas 11-12), "um quadro de otimismo" (linha 12) e "para favorecer a consumação final do golpe revestido de impeachment" (linhas 12-13).

O trecho que se estende da linha 15 a 37, desenvolve o segundo SbT mínimo, que rotulamos como Projeção de medidas otimistas e sugestivas de crescimento. Nesse trecho, projetam-se as medidas, tanto em termos políticos como econômicos, propostas pelo governo em busca de apoio popular e legitimidade que endossariam a preparação de um quadro otimista para o impeachment. Pode-se verificar, na integração dos enunciados do trecho em pauta, a alusão a um conjunto de referentes, concernentes entre si, que instauram a propriedade da centração em torno do referido subtópico, o que se vê, principalmente, em enunciados como "haverá crescimento" (linha 24) e "a Caixa Econômica Federal voltará a financiar imóveis" (linha 30). 
Por fim, o excerto da linha 38 a 44 compreende o tópico 2, desenvolvido no SbT mínimo 3, que se intitula como Golpe preparado com leis retorcidas provoca resignação. Nesse SbT, demonstra-se o cenário ideal para a confirmação do golpe, que contaria com o consentimento da população, realçando que o golpe seria o resultado de leis postas ao avesso e interpretações convincentes, o que geraria o sentimento de resignação. O delineamento desse SbT manifestase, então, por meio da formulação de um grupo de referentes que estabelecem a concernência entre os enunciados, conforme se pode observar nas seguintes passagens: "os congressistas aproveitam as férias" (linha 39), "O golpe não foi feito com tanques" (linhas 42-43), "mas com leis" (linha 43), e "isso gera resignação" (linha 44).

A organização intertópica do artigo de opinião em apreço, em que o tópico global se subdivide em dois tópicos mais específicos, um dos quais se subdivide em outros dois mais específicos ainda, pode ser representada conforme o esquema a seguir:

Tópico global: Preparação de quadro otimista para consumação do golpe final do impeachment

Tópico 1: Delineamento de cenário otimista para impeachment

Tópico 1.1 (SbT mínimo 1): Desenho de quadro otimista: divulgação de apenas notícias boas

Tópico 1.2 (SbT mínimo 2): Projeção de medidas sugestivas de crescimento

Tópico 2 (SbT mínimo 3) : Golpe preparado com leis retorcidas provoca resignação

Ainda sobre o grau de complexidade da hierarquização tópica em artigos de opinião, a pesquisa também compreendeu a análise da quantidade de QTs por artigo. Os dados analisados demonstraram que a maioria dos artigos apresenta apenas um QT (60\% dos casos), e, portanto, dois níveis hierárquicos. Esses são casos em que esse gênero, via de regra, é constituído por um único tópico global (ST) que se desdobra em SbTs, e nenhum destes subdivide-se em outros SbTs ainda mais particulares. Os casos menos recorrentes (embora também expressiva) incidiram sobre os artigos que apresentam dois QTs (40\% dos casos), estruturados, portanto, em três níveis na hierarquia tópica. Esses são os casos em que o tópico global se desenvolve em SbTs particulares, e algum destes subdivide-se em tópicos ainda mais específicos.

$\mathrm{O}$ artigo de opinião da figura, ilustra os casos menos frequentes, isto é, aqueles em que os artigos são compostos por dois QTs, portanto, três níveis de hierarquia tópica. Nesses casos, o tópico central desenvolve-se em dois tópicos mais específicos e um destes se desdobra em outros dois tópicos mais particularizadores. A figura 3, a seguir, ilustra a hierarquia tópica instaurada no artigo em pauta: 
Figura 3 - Hierarquia tópica em dois QTs

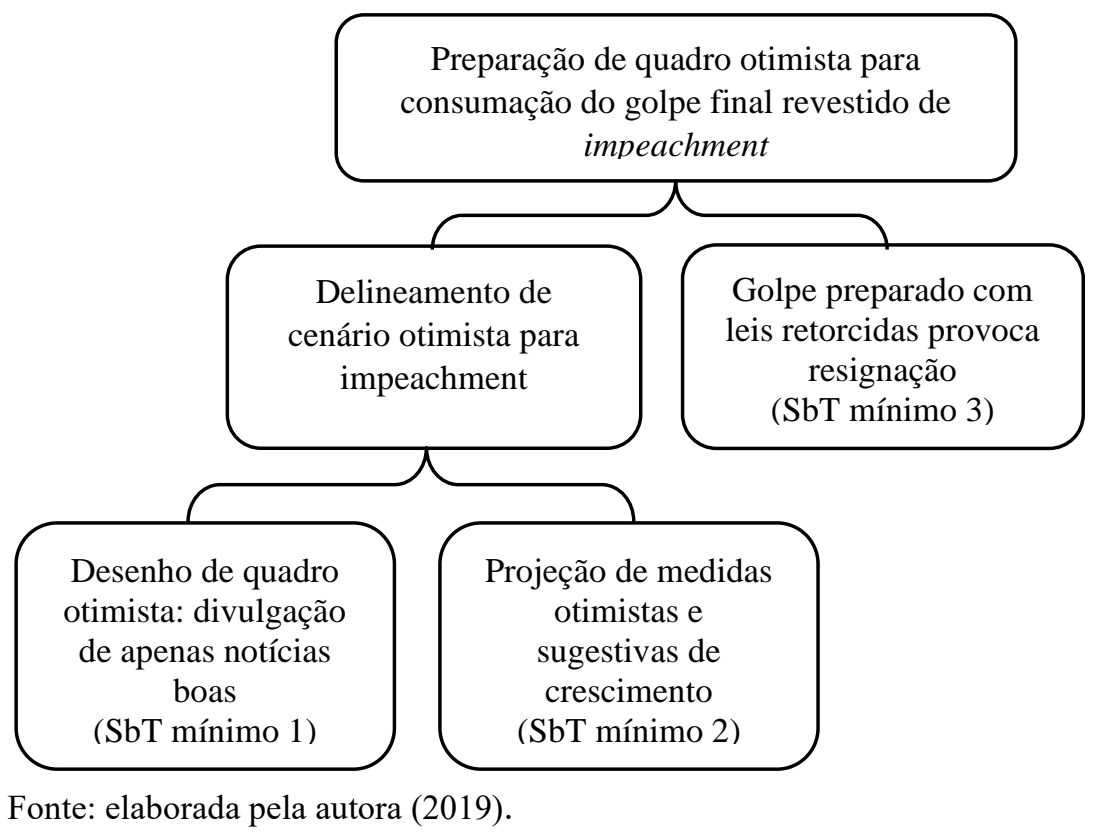

Nesse exemplo, conforme percebe-se, o tópico central do artigo de opinião em análise desenvolve-se em dois tópicos discursivos mais particulares que compõem o segundo nível da hierarquia. Mediante esse desdobramento, o tópico central caracteriza-se como um ST e os dois tópicos mais particulares em relação ao tópico central se estabelecem como SbTs constituindo o primeiro QT do texto. É, então, nesse sentido, que se pode afirmar, em consonância com Jubran (2015b), que o estatuto ST e SbT é relacional. À vista disso, quando um SbT se subdivide em tópicos ainda mais particulares, este $\mathrm{SbT}$ passa a ser um ST relativamente aos tópicos que o compõem. A subdivisão do SbT Delineamento de cenário otimista para impeachment em dois mais específicos, do terceiro nível de hierarquização tópica, motiva este SbT a assumir o estatuto de ST no que se refere aos seus dois tópicos coconstituintes, cuja a configuração que exibem como SbTs, concentram-se, respectivamente, nas ideias Desenho de quadro otimista: divulgação de apenas notícias boas e Projeção de medidas otimistas e sugestivas de crescimento. Nesse contexto, essa subdivisão progressiva do exemplo ilustrado (figura 2), dá origem a mais um QT, de nível inferior na hierarquia tópica.

Nosso estudo também envolveu a análise de organização intertópica linear, isto é, a análise do sequenciamento dos tópicos na linearidade textual. Mais especificamente, buscamos verificar como esse gênero textual se caracteriza quanto ao uso das estratégias de linearização, identificando, particularmente, as formas predominantes.

Nessa direção, ao manifestarem complexidade hierárquica, os artigos de opinião em estudo naturalmente também revelam traços regulares quanto à complexidade sequencial. Nesse caso, a particularidade do gênero é o emprego exclusivo da estratégia de continuidade 
tópica. O exemplo comentado na figura 2 demonstra o emprego dessa estratégia de linearização. Nesse caso, percebe-se que cada SegT mínimo desenvolve um tópico de modo que seja possível reconhecer uma completude de desenvolvimento tópico e, somente após seu esgotamento, um novo tópico é introduzido e desenvolvido, sem perturbação na distribuição dos tópicos na linha discursiva. Desse modo, assim como foi destacado na discussão da quantidade de tópicos discursivos e de QTs por artigo, a análise a respeito das formas de linearização tópica nos artigos de opinião revelou que esse gênero se caracteriza por uma sólida regularidade na sua organização tópica.

As análises relativas à organização intertópica no plano hierárquico e linear aqui empreendidas mostraram que o gênero em estudo se caracteriza pela alta regularidade manifestada nos seguintes aspectos: (i) desdobramento do tópico global em três, quatro, cinco, seis, sete, oito ou nove SbTs mínimos, com preferência por uma divisão que envolva de três (principalmente) a cinco SbTs mínimos; (ii) subdivisão do tópico global em tópicos mais específicos organizados em um ou dois QTs por artigo (com predominância de um QT) e (iii) predomínio absoluto da continuidade tópica no sequenciamento dos tópicos.

Demonstrada à análise intertópica hierárquica e sequencial nos artigos de opinião, passamos, na sequência, à discussão dos resultados obtidos no estudo em relação à organização interna dos SegTs mínimos, isto é, à organização intratópica.

A análise pautou-se na hipótese de que a organização intratópica do gênero em apreço, estaria, possivelmente, fundada na combinação de duas unidades de estruturação intratópica, posição-suporte, conforme definidas em Penhavel (2010), a partir do estudo de relatos de opinião.

A esse respeito, os dados mostraram que, de fato, a organização intratópica dos artigos em análise está assentada na relação entre as unidades de posição e suporte. Verificou-se que essa relação foi identificada em 98,93\% dos SegTs mínimos que compõem os artigos do nosso corpus. Isso equivale dizer que a estruturação interna de SegTs nesse gênero também se constitui como um processo sistemático, que se organiza, tal como nos relatos de opinião, com base no princípio central-subsidiário, ou combinação posição-suporte.

Os SegTs mínimos nas figuras 4 e 5, a seguir, extraídos do artigo de opinião analisado acima, ilustra a regra geral da alternância entre as unidades posição-suporte: 
Figura 4 - Alternância da relação posição-suporte

Há alguns dias, o Brasil começou a parecer um país agradável nos telejornais, especialmente no Jornal Nacional, notícias amenas e apresentadores serenos. Os jornais deixaram de falar de uma paisagem devastada e começaram a dar notícias boas: "Cresce o otimismo com a economia", anunciou o Datafolha divulgando uma pesquisa pouco convincente, tanto em

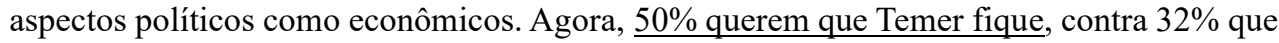
preferem a volta de Dilma. Em abril o instituto apurou que a maioria não queria Dilma nem Temer. $61 \%$ aprovavam o impeachment dela, e 58\% o dele. Alguma fada deve estar protegendo Temer porque nada mudou no cenário que justifique tal guinada do sentimento popular. Nesta terça-feira, por sinal, ele deu um prazo de 20 dias para que seus ministros da área econômica apresentem medidas para estimular o crescimento. Tal prazo termina quando? Em agosto, ora, bolas. E tem a Olimpíada, que absorverá muita luz nas próximas semanas, deixando em segundo plano os problemas reais.

Não há dúvida: começou a ser pintado, com cores suaves, um quadro de otimismo para favorecer a consumação final do golpe revestido de impeachment em agosto. Uma pintura em aquarela, com muita cor borrada e pouca nitidez das formas (A pintura da paisagem para o golpe, Página 20, 19 jul. 2016).

Fonte: elaborada pela autora (2019).

O artigo do qual extraímos o exemplo da figura 4, conforme a análise mostrada acima, destaca a preparação de quadro otimista para consumação do golpe final do impeachment. Nesse contexto, com base na propriedade de centração, pode-se afirmar que o tópico ilustrado em (4) focaliza a ideia Desenho de quadro otimista: divulgação de apenas notícias boas. Como realçam os trechos destacados no exemplo, o conjunto de enunciados expressos nas linhas 1-14 tratam de aspectos subsidiários relativos à ideia central do tópico, abordando, especificamente, a divulgação de notícias boas e dados convincentes que confluem para a projeção de um cenário otimista e favorável ao impeachment da presidenta Dilma Rousseff, como evidenciam os enunciados “o Brasil começou a parecer um país agradável nos telejornais” (linha 1), "Cresce o otimismo com a economia, anunciou o Datafolha" (linha 3-4), enquanto os trechos sublinhados nas linhas 13-15, apresentam o tópico do SegT, ou seja, manifestam diretamente a ideia nuclear do SegT. Em vista disso, denominam-se os enunciados nas linhas 1-14 de suporte e os enunciados nas linhas de 13-15, de posição.

O SegT na figura 5 mostra mais um caso em que identificamos as unidades de organização intratópica de posição e suporte: 
Figura 5 - Alternância da relação posição-suporte

Na política, o Governo emplacou Rodrigo Maia na presidência da Câmara para tocar sua agenda conservadora, começando pela PEC que aprisiona o crescimento do gasto público no índice da inflação e pela reforma previdenciária. Da agenda de agosto Temer tratará esta noite num jantar com Rodrigo e Renan Calheiros, presidente do Senado. Quando o Congresso reabrir, no início de agosto, Meirelles e sua equipe estarão apresentando medidas pró-crescimento. Se elas fossem de fato possíveis e viáveis, já estariam sendo aplicadas, não estaria o governo perdendo um precioso tempo.

Não importa o recheio do bolo, importa que tenha glacê vistoso, que agora começará a ser preparado com muito açúcar.

Até o FMI apareceu neste início de semana informando que a recessão pode acabar $\underline{\text { sendo alguns décimos menores este ano, em relação ao que previra, e que em } 2017}$ haverá crescimento, ainda que seja apenas de $0,5 \%$. Mas nada como o Datafolha, ao informar que os otimistas com a economia são $38 \%$, contra $30 \%$ de pessimistas. E numa contradição com os $60 \%$ que esperam aumento da inflação e do desemprego. Mas o que importa é a manchete, e ela falou de aumento do otimismo econômico. Na linha do otimismo, apesar da inflação, do desemprego e do paradeiro nos negócios, fomos também informados de que:

- A Caixa Econômica Federal voltará a financiar imóveis para a classe média.

- Temer pediu à equipe econômica que reduza os juros.

- As exportações podem ter um superávit de US\$ 46,934 bilhões na balança comercial deste ano.

- Segundo a CNI, o Índice de Confiança do Empresário Industrial teve a terceira alta seguida em julho, passando de 45,7 pontos para 47,3.

- Segundo o Credit Default Swap (CDS), com a posse de Temer o risco Brasil caiu significativamente, passado de 495,09 pontos em dezembro passado para 294,35 neste mês de julho (A pintura da paisagem para o golpe, Página 20, 19 jul. 2016).

Fonte: elaborada pela autora (2019).

A nosso ver, o tópico do SegT acima pode ser intitulado Projeção de medidas otimistas e sugestivas de crescimento. Nesse exemplo, percebe-se que o segundo grupo de enunciados destacado nas linhas 9-10, manifesta esse tópico de forma direta, o que nos permitiu, portanto, considerar esse trecho como a unidade de posição do segmento.

Note-se também que o primeiro conjunto de enunciados (linhas 1-8) e o terceiro (linhas 11-27) podem ser identificados como duas unidades de suporte, tratando, cada uma, de aspectos secundários relativamente à ideia nuclear do tópico. Nas linhas 1-8, a concernência específica gira em torno das Medidas otimistas de crescimento no âmbito político propostas pelo governo em busca de apoio popular e legitimidade que endossariam a preparação de um quadro favorável ao impeachment, conforme sugere a passagem "Meirelles e sua equipe estarão apresentando medidas pró-crescimento" (linhas 5-6). No trecho que compreende as linhas 1127, a concernência decorre, principalmente, em relação às Medidas otimistas de crescimento no âmbito econômico, como indicam as passagens "Temer pediu à equipe econômica que reduza os juros" (linha 23) e "As exportações podem ter um superávit" (linhas 21).

Como mencionado, a relação posição-suporte pode manifestar-se, em cada domínio, sob diferentes formas de combinação: posição-suporte, posição-suporte-suporte, suporteposição, suporte-posição-suporte, posição-suporte-suporte-suporte etc. O SegT mínimo na 
figura 4 acima ilustra a combinação suporte-posição. Em (5), o SegT mínimo exemplifica a sequência suporte-posição-suporte. De acordo com esse aspecto, verificamos em nossos dados a existência de uma considerável padronização também em termos de combinações das unidades de posição-suporte. Dentre os agrupamentos identificados, dois se destacam como os mais frequentes - posição-suporte e posição-suporte-suporte -, que, juntos, respondem por $56,87 \%$ dos casos. Os demais casos se distribuem por vários tipos diferentes de combinação.

O SegT mínimo, a seguir, extraído de outro ${ }^{8}$ dos artigos de opinião analisados na pesquisa, ilustra a regra geral da combinação posição-suporte, isto é, o caso mais recorrente identificado em nossos dados. Além disso, esse SegT ilustra a recursividade da relação posiçãosuporte, uma vez que apresenta mais de um domínio de estruturação intratópica, assinalando que as unidades de posição e suporte também se particularizam baseada nessa mesma relação.

Sobre esse aspecto, os dados identificaram que na maior parte dos casos $(87,24 \%)$, os SegTs mínimos componentes dos artigos de opinião apresentam apenas um domínio de estruturação intratópica, como, se pode verificar, por exemplo, no SegT mínimo em (3) analisado acima. Apuramos também SegTs mínimos constituídos por dois domínios - um primeiro domínio equivalente ao SegT inteiro e um segundo domínio equivalente à estruturação interna de um Suporte - e por três domínios, mas com pouca frequência. Consideramos que, no gênero em estudo, a aplicação recursiva da relação posição-suporte e a instauração de mais de um domínio por SegT não constituem um traço fortemente caracterizador, mas não podem ser desprezadas, já que, de fato, participam da estruturação interna de SegTs do corpus, num percentual até considerável, somando-se SegTs formados por dois e por três domínios $(12,76 \%$ dos casos). Em (6a-b), demonstramos essa recursividade:

Figura 6a - Recursividade da relação posição-suporte

É torturante, igualmente ter que aceitar essa situação insolúvel do sistema penal no Brasil.

O tempo passa e a questão carcerária se agrava mais e mais, a exemplo de outros problemas sociais que nos afligem diariamente sem que tenhamos, na condição de sociedade organizada, uma solução pelo menos plausível que nos garanta o mínimo de confiança nas instituições que administram o erário, e olha que não é pouco o que se arrecada, através duma política tributária opressora, da já quebrada economia do cidadão comum. Sei que existem especialistas da área que tentam explicar, os inexplicáveis motivos que geram essa superlotação dos presídios que fazem estourar a todo o momento, aqui e lá, nas "casas de detenções" motins que quase sempre acabam em mortes./ Estatísticas recentes, falam que o Brasil tem a quarta maior população carcerária do mundo./ São mais de 550 mil presos e, dizem, que há quase o mesmo número do lado de fora, isto é zanzando por aí em meio aos citadinos, que deveriam cumprir pena, por algum delito cometido, e não cumprem pela falta de espaço nos presídios (Nossos Terrores!, A Gazeta, 19 de ag. de 2016).

Fonte: elaborada pela autora (2019).

\footnotetext{
${ }^{8}$ O SegT mínimo analisado em (6a-b) foi extraído do artigo de opinião Nossos terrores!, publicado no jornal $A$ Gazeta, em 19 de agosto de 2016.
} 
Segundo nossa análise, o tópico do SegT na figura 6a, pode ser nomeado Falência do sistema penal brasileiro. Note-se que o primeiro enunciado destacado no exemplo, linha 1, estabelece esse tópico de modo direto, motivando, desse modo, a classificá-lo como uma unidade de posição do segmento.

Os grupos de enunciados nas linhas 2-14, identificados como suporte, manifestam uma ideia subsidiária no interior do SegT em relação ao seu tópico. Conforme realçado, esses grupos de enunciados abordam a superlotação carcerária como mais um grave problema social insolúvel que aflige a sociedade brasileira, referenciada, nesse SegT, por meio de enunciados que materializam o princípio da centração tópica, conforme se vê, especialmente, em "a questão carcerária se agrava mais e mais" (linha 2), "essa superlotação dos presídios" (linha 8) e "sempre acabam em mortes" (linha 9-10) e discutem a ideia de que o Brasil, segundo estatísticas, teria uma grande população carcerária, o que pode ser considerado como indicação de que, de fato, a população carcerária é um dos graves problemas insolúveis no Brasil, de acordo com a concernência do trecho "Estatísticas recentes, falam que o Brasil tem a quarta maior população carcerária do mundo" (linhas 10-11).

No SegT em pauta, é possível ainda perceber que a unidade de suporte pode ser interpretada em duas partes, ou seja, também se organiza internamente segundo o princípio central-subsidiário ou posição-suporte. Nesse caso, o tópico do SegT nas linhas 10-11 (a partir da barra) centra-se na ideia de que o Brasil, segundo estatísticas recentes, teria uma grande população carcerária, conforme sugerem os trechos sublinhados nessas linhas (até a barra). As linhas 11-14 (depois da barra), por sua vez, elaboram referências que especificam tais estatísticas e qual seria a referida população carcerária brasileira, como mostram os trechos "mais de 550 mil presos" (linha 11) e "o mesmo número do lado de fora" (linha 12). Nesse contexto, no âmbito do SegT como todo, o segmento nas linhas 2-14 assume estatuto de suporte, enquanto que, no âmbito do trecho nas linhas 10-14, as linhas 10-11 (entre as barras) fundamse como uma posição e as linhas 11-14 (após a barra), como suporte. O SegT mínimo em (6a) pode, então, ser analisado como em (6b):

Figura $6 \mathrm{~b}$ - Recursividade da relação posição-suporte

É torturante, igualmente ter que aceitar essa situação insolúvel do sistema penal no Brasil. O tempo passa e a questão carcerária se agrava mais e mais, a exemplo de outros problemas sociais que nos afligem diariamente sem que tenhamos, na condição de sociedade organizada, uma solução pelo menos plausível que nos garanta o mínimo de confiança nas instituições que administram o erário, e olha que não é pouco o que se arrecada, através duma política tributária opressora, da já quebrada economia do cidadão comum. Sei que existem especialistas da área que tentam explicar, os inexplicáveis motivos que geram essa superlotação dos presídios que fazem estourar a todo o momento, aqui e lá, nas "casas de detenções" motins que quase sempre acabam em mortes. 


\begin{tabular}{|l|l|}
\hline Estatísticas recentes, falam que o Brasil tem a quarta maior população carcerária do & 11 \\
mundo. & 12 \\
São mais de 550 mil presos e, dizem, que há quase o mesmo número do lado de & 13 \\
fora, isto é zanzando por aí em meio aos citadinos, que deveriam cumprir pena, & 14 \\
por algum delito cometido, e não cumprem pela falta de espaço nos presídios & 15 \\
(Nossos Terrores!, A Gazeta. 19 de ag. de 2016). & 16 \\
\hline
\end{tabular}

Fonte: Elaborada pela autora (2019).

Desse modo, instauram-se, no SegT em análise, considerando sua representação em (6a), dois domínios de estruturação intratópica: domínio 1 (linhas 1-16), constituído por uma unidade de posição (linha 1) e uma unidade de suporte (linhas 2-16); em (6b), instaura-se o domínio 2 (linhas 11-16), formado também por uma unidade de posição (linhas 11-12) e uma unidade de suporte (linhas 13-16).

Em síntese, com base nos dados apurados e nos exemplos analisados acima, consideramos que a organização intratópica nos artigos de opinião, isto é, a estruturação interna dos SegT mínimos componentes dos artigos analisados configura como unidades linguísticotextuais altamente regulares, visto que manifestam uma regra geral de estruturação interna sistematizada com base na combinação de duas unidades intratópicas - posição e suporte.

Conforme argumentamos, essas duas unidades podem subdividirem-se, no interior do SegT, fundadas na mesma relação estabelecida no âmbito do SegT como todo, motivando, desse modo, a instauração de SegTs com dois ou três domínios, além da própria estruturação de SegTs com apenas um domínio (sem recursividade), com predominância deste último caso.

Para além dessas questões, buscamos demonstrar, também, que os conjuntos de enunciados com estatuto de posição e aqueles com estatuto de suporte podem se estruturar de diversos modos no interior de cada um dos domínios que os compõem, gerando combinações como posição-suporte, posição-suporte-suporte, suporte-posição-suporte, dentre outras. Tais possibilidades de formação de variadas combinações com base nas mesmas unidades de estruturação intratópica também corroboram o fato de que o princípio posição-suporte ou centralidade-subsidiariedade, encontra-se na base da organização intratópica dos SegTs nos artigos de opinião.

\section{Conclusão}

Procuramos demonstrar, aqui, com a análise da Organização Tópica em artigos de opinião se a organização intertópica e a organização intratópica, nesse gênero, se configurariam como processos sistemáticos passíveis de serem definidos, em termos de organização tópica. Nesse sentido, a análise mostrou que, de fato, há sistematicidade nos dois processos constituintes da organização tópica. No que diz respeito à organização intertópica, a análise 
evidenciou traços de regularidades manifestados nos seguintes aspectos: desdobramento do tópico global em três, quatro, cinco, seis, sete, oito ou nove SbTs mínimos, com preferência por uma divisão que envolva de três (principalmente) a cinco SbTs mínimos; subdivisão do tópico global em tópicos mais específicos organizados em um ou dois QTs por artigo (com predominância de um QT) e predomínio absoluto da continuidade tópica no sequenciamento dos tópicos. No que tange à organização intratópica, a análise empreendida demonstrou a existência de sistematicidade na estruturação interna dos SegTs mínimos nos artigos de opinião na medida em que o interior desses SegTs se organizam, segundo a combinação potencialmente recursiva das unidades de organização intratópica posição e suporte.

Enfim, ao demonstrar as regularidades no processo de Organização tópica em um gênero particular, como o artigo de opinião, acredita-se que este trabalho não pretendeu esgotar os dados, nem construir uma análise acabada do funcionamento desse processo em nesse gênero. Ao contrário, novos e mais pontos de questionamentos devem ser lançados, para se buscar outras conclusões, também provisórias, na procura de contribuir com a pesquisa na área de Linguística Textual e, em particular, da GTI, no sentido de conferir-lhe uma maior sistematização e validação enquanto proposta genuinamente brasileira de gramática de texto.

\section{Referências}

CAVALCANTE, M. M. et al. O texto e suas propriedades: definindo perspectivas para análise. Revista (Con)Textos Linguísticos, Vitória, v. 13, n. 25, p. 25-39, 2019.

JUBRAN, C. C. A. S. Inserção: um fenômeno de descontinuidade na organização tópica. In: CASTILHO, A. T. (Org.). Gramática do português falado. v. III. Campinas: Editora da Unicamp, 1993. p. 241-259.

JUBRAN, C. C. A. S. Introdução. In: JUBRAN, C. C. S. A. (Org.). Gramática do português culto falado no Brasil. v. 1. Campinas: Editora da Unicamp, 2015a. p. 27-36.

JUBRAN, C. C. A. S. Tópico Discursivo. In: JUBRAN, C. C. S. A. (Org.). Gramática do português culto falado no Brasil. v. 1, Campinas: Editora da Unicamp, 2015b. p. 89-132.

JUBRAN, C. C. A. S. Uma gramática textual de orientação interacional. In: CASTILHO, A. T. et al. (Org.). Descrição, história e aquisição do português brasileiro. Campinas: Pontes, 2007. p. 312-327.

PENHAVEL, E. Estudo do processo de estruturação interna de Segmentos Tópicos Mínimos em diferentes gêneros textuais. Relatório Final de Pesquisa. São José do Rio Preto, Universidade Estadual Paulista, 2017. 
PENHAVEL, E.; DINIZ, T. C. G. O processo de estruturação interna de Segmentos Tópicos Mínimos em Cartas de Leitores mineiras do início do século XXI. Revista (Con)Textos Linguísticos, Vitória, v. 8, n. 11, p. 21-38, 2014.

PENHAVEL, E. Marcadores Discursivos e Articulação Tópica. 2010. 168f. Tese (Doutorado em Linguística) - Instituto de Estudos da Linguagem, Universidade Estadual de Campinas, Campinas, 2010.

PINHEIRO, C. L. Estratégias textuais-interativas: a articulação tópica. Maceió: EDUFAL, 2005.

\section{Sobre a autora}

Cleide Vilanova Hanisch (Orcid iD: https://orcid.org/0000-0001-9681-1438)

Doutora em Estudos Linguísticos pela Universidade Estadual Paulista (Unesp/Ibilce) - câmpus São José do Rio Preto; mestra em Letras pela Universidade Federal do Acre (UFAC); graduada em Letras Português pela Universidade Federal do Acre (UFAC). É professora do curso de Letras Português e do curso de Pedagogia da Universidade Federal do Acre (UFAC), câmpus Floresta, Cruzeiro do Sul.

Recebido em maio de 2021.

Aprovado em agosto de 2021. 